\author{
Abstracta Iranica \\ Abstracta Iranica Revue bibliographique pour le domaine irano-aryen \\ Volume 42-43 | 2021 \\ Comptes rendus des publications de 2019-2020
}

\title{
Sepideh Qaheri, Objets égyptiens et égyptianisants d'époque achéménide conservés en Iran
}

Julien Cuny

\section{OpenEdition}

Édition électronique

URL : https://journals.openedition.org/abstractairanica/52548

DOI : 10.4000/abstractairanica.52548

ISSN : 1961-960X

Éditeur :

CNRS (UMR 7528 Mondes iraniens et indiens), Éditions de l'IFRI

Référence électronique

Julien Cuny, « Sepideh Qaheri, Objets égyptiens et égyptianisants d'époque achéménide conservés en Iran », Abstracta Iranica [En ligne], Volume 42-43 | 2021, document 37, mis en ligne le 15 avril 2021 consulté le 14 décembre 2022. URL : http://journals.openedition.org/abstractairanica/52548 ; DOI : https://doi.org/10.4000/abstractairanica.52548

Ce document a été généré automatiquement le 14 décembre 2022.

Tous droits réservés 


\title{
Sepideh Qaheri, Objets égyptiens et égyptianisants d'époque achéménide conservés en Iran
}

\author{
Julien Cuny
}

\section{RÉFÉRENCE}

Sepideh Qaheri, Objets égyptiens et égyptianisants d'époque achéménide conservés en Iran.

Leuven: Peeters, 2020. 280 p. (Persika, 20), ISBN : 978-90-429-4288-2.

1 Catalogue bilingue français-persan de 114 objets, désignés globalement comme aegyptiaca conservés dans les musées de Téhéran (71), de Persépolis (18) et de Suse (25).

2 Le corpus rassemble des objets variés, certains déjà bien connus mais surtout de nombreux inédits sortis des réserves de ces musées, réunis en quatre catégories, chacune introduite par une présentation qui s'avèrera particulièrement utile pour l'iranisant peu familier du monde égyptien. L'ensemble est richement documenté, la plupart des objets étant illustrés par une photographie et un ou plusieurs dessins.

3 La première catégorie (A) rassemble les « Décors architecturaux, Reliefs et inscriptions, Statuaire royale » (14 objets). On y trouvera notamment une synthèse à jour sur la célèbre statue de Darius découverte (non pas «fortuitement », cf. p. 24) à Suse en 1972. L'A. rappelle en particulier l'hypothèse d'E. Brecciani reprise par J. Yoyotte concernant son lieu de destination d'origine, qu'il faut avec eux situer à Pithom plutôt qu'à Héliopolis. On notera dans cette catégorie un ensemble très intéressant de dix fragments de cornes en bleu égyptien appartenant à des sculptures composites auparavant uniquement connus par trois dessins d'E. Schmidt.

4 La catégorie B regroupe les « Amulettes et objets magiques » (23 objets). Les amulettes, généralement en faïence, ont été trouvées en Iran en nombre relativement important et l'A. renouvelle l'hypothèse de l'existence d'ateliers de production locaux plutôt que d'importations. Cet ensemble atteste la diffusion des pratiques médico-magiques et 
prophylactiques égyptiennes au sein même de la cour de Perse, et donc certainement de la présence de médecins égyptiens, maintes fois mentionnée dans diverses sources historiques.

5 La catégorie la plus nombreuse (C) comprend les «Contenants et récipients de luxe » (71 objets), principalement des alabastres, ainsi que des assiettes ou plateaux à fond plat ou sur piédouche. Enfin, 6 « objets divers » (bijou, éléments d'incrustation, ivoires) constituent un dernier groupe (D).

6 Le catalogue rassemble ainsi des objets clairement produits en Égypte ou par des Égyptiens, aussi bien que des objets peut-être produits en Perse selon des modèles inspirés par l'Égypte, la question du lieu de production étant abordée avec prudence en l'absence d'analyse pétrographique. On peut regretter toutefois que les critères de sélection n'aient toujours été clairement explicités: on ne comprend pas très bien pourquoi par exemple les plateaux anépigraphes en pierre dure de Persépolis n'ont pas été inclus, alors qu'ils sont "du même type » qu'un exemplaire portant une inscription hiéroglyphique (on s'étonne d'ailleurs que l'A. considère ces plats anépigraphes comme "inachevés, du moins en partie», p. 102). On peut faire la même remarque pour certains carreaux d'applique en bleu égyptien qui n'ont pas été inclus. Ils sont pourtant identiques au $\mathrm{n}^{\circ} \mathrm{A} 1.10$ mais sans le motif au faucon (l'un est pourtant illustré p. 43). Ces hésitations, compréhensibles, montrent surtout la difficulté à définir des frontières nettes à ces productions et à appréhender clairement leur identité dans un environnement fortement marqué par l'interculturalité. En revanche, les objets égyptiens d'époque saïte ( $26^{\mathrm{e}}$ dynastie) trouvés en Iran, certainement spoliés par les rois perses, ont été judicieusement inclus au corpus.

7 L'ouvrage, qui se veut à la fois à l'usage des égyptologues et des spécialistes de la Perse, est introduit par de courts textes permettant au lecteur de recontextualiser les découvertes et la problématique de la présence de ces objets loin de l'Égypte. Ils offrent en effet l'intérêt d'avoir tous été découverts lors de fouilles archéologiques sur les grands sites impériaux achéménides d'Iran. L'A. s'est donc particulièrement efforcée de retrouver la provenance de chacun d'entre eux, tâche parfois malaisée. Ainsi, contrairement à ses hésitations, la stèle d'Horus sur les crocodiles (B 5.1) provient bien de Suse ainsi que le démontre une photographie attachée au rapport de $R$. de Mecquenem pour la campagne de 1931, rapport qui la mentionne également, mais sans en préciser le secteur de découverte.

8 Comme le précise l'A., le corpus des aegyptiaca d'Iran achéménide devrait être complété par les objets que la règlementation en vigueur alors a fait parvenir à Paris (pour Suse) et Chicago (pour Persépolis) ainsi que par les quelques découvertes erratiques mentionnées en passant mais auxquelles elle n'a pas pu avoir accès. Cette tâche est en cours avec l'étude qu'elle réalise actuellement sur les alabastres de Suse conservés à Paris. 


\section{AUTEURS}

JULIEN CUNY

Louvre, Paris 